\title{
EDUCAÇÃO INFANTIL: O CONSENSUAL NAS REPRESENTAÇÕES SOCIAIS DE PAIS E MÃES DE CRIANÇAS
}

\author{
EARLY CHILDHOOD EDUCATION: THE CONSENSUS ON SOCIAL \\ REPRESENTATIONS OF PARENTS AND CHILDREN OF MOTHERS
}

\section{EDUCACIÓN INFANTIL: EL CONSENSO EN REPRESENTACIÓN SOCIAL DE PADRES Y MADRES DE NIÑOS}

\author{
Laeda Bezerra Machado* \\ Professora vinculada ao Departamento de Administração Escolar e Planejamento \\ Educacional e Programa de Pós-graduação em Educação Núcleo de Formação de \\ Professores e Prática Pedagógica da Universidade Federal de Pernambuco (UFPE), \\ Recife, Pernambuco, Brasil \\ Luciana Oliveira Freitas Monteiro** \\ Professora de Educação Infantil do Centro Educacional Carochinha
}

Resumo: O artigo identifica o consenso das representações sociais de Educação Infantil entre pais e mães de crianças matriculadas nessa etapa da educação. Adotou-se a Teoria das Representações Sociais, particularmente, a abordagem societal, de W. Doise. Participaram da pesquisa 108 sujeitos. Para coletar dados utilizou-se um questionário com escala. $\mathrm{Na}$ análise do material foram consideradas as frequências das escolhas por item. O campo comum das representações sociais dos participantes ancorou-se em aspectos acadêmicos, normativos e atualizados sobre Educação Infantil, representada como espaço de desenvolvimento e aprendizagem da criança. Infere-se que esse consenso decorre do acesso a diferentes formas de comunicação a que estão expostas essas famílias.

Palavras-chave: Educação Infantil. Representações Sociais. Famílias. Consenso.

\footnotetext{
* Doutora em Educação pela Universidade Federal do Rio Grande do Norte; Mestre em Educação pela Universidade Federal de Pernambuco.

** Mestre em Educação pela Universidade Federal de Pernambuco; Graduada em pedagogia pela Universidade Federal de Pernambuco.
} 
Abstract: The article identifies the consensus of the social representations of early childhood education between fathers and mothers of children enrolled in this educational stage. He adopted the theory of social representations, particularly the societal approach of $W$. Doise. The participants were 108 subjects. To collect data we used a questionnaire with scale. In the material analysis we considered the frequency of choices per item. The common ground of social representations of the participants was anchored in academic aspects, regulatory and updated on Early Childhood Education, represented as a child's development and learning space. It is inferred that this consensus arises from access to different forms of communication they are exposed to these families.

Keywords: Early Childhood Education. Social representations. Families. Consensus.

Resumen: El artículo identifica el consenso de las representaciones sociales de la educación infantil entre los padres de los niños inscritos en esta etapa educativa. Adoptó la teoría de las representaciones sociales, en particular el enfoque social de W. Doise. Los participantes fueron 108 sujetos. Para recoger los datos se utilizó un cuestionario con escala. En el análisis de materiales que consideramos la frecuencia de las elecciones por artículo. La base común de las representaciones sociales de los participantes estaba anclado en aspectos académicos, reguladores y actualizados sobre la Educación de la Primera Infancia, representado como el desarrollo de un niño y el espacio de aprendizaje. Se infiere que este consenso surge de acceso a las diferentes formas de comunicación que están expuestos a estas familias. Palabras clave: Educación infantil. Representaciones sociales. Familias. Consenso.

\section{INTRODUÇÃO}

No Brasil, ao longo das últimas quatro décadas, os direitos da criança vêm se constituindo de forma gradual e a legislação educacional brasileira que contempla esse grupo é recente. Ao longo da história as reformas educacionais brasileiras destinaram-se a regular os níveis mais elevados da educação, restando para as crianças, sobretudo as de baixa renda, um atendimento assistencial.

Os anos 1980 ficaram conhecidos como anos de crítica ao modelo assistencialista do atendimento direcionado à infância, pois, na época, não se utilizava a expressão Educação Infantil. Naquele período, foi sendo produzida e divulgada uma literatura crítica aos programas compensatórios, que defendia a função pedagógica das creches e pré-escolas, que deveriam ser consideradas não apenas como lugares de cui- 
dar e guardar a criança, mas como espaços destinados à promoção do desenvolvimento infantil, em todos os aspectos.

Conforme afirma Corrêa (2002), a década de 1980, período de discussão, elaboração e promulgação da Constituição Federal, foi, também, marcado por discussões teóricas e lutas da sociedade civil em favor do atendimento educacional para as crianças na esfera pública. Tais movimentos reivindicatórios contaram com a participação de mulheres oriundas das classes populares, que estavam conquistando espaço no mercado de trabalho e, também, as camadas médias da sociedade envolveram-se com esses movimentos, que exigiam a criação de instituições coletivas para as crianças.

Os profissionais da educação, por meio de suas associações representativas, participaram de modo efetivo das discussões de temas e tópicos que foram tratados pela atual Carta Magna do Brasil. Podemos afirmar que manifestações de professores interferiram para garantir às crianças pequenas o direito à educação.

A Constituição de 1988 é um marco na história brasileira, pois promoveu a garantia de direitos sociais que, anteriormente, eram negados à população brasileira. Nesta Carta há referências específicas à Educação Infantil, por exemplo, no Inciso IV do Art. 208 está firmada a garantia do atendimento às crianças de zero a seis $\operatorname{anos}^{1} \mathrm{em}$ creches e pré-escolas.

O Estatuto da Criança e do Adolescente (ECA), Lei n. 8.069 de 13 de julho de 1990, contém um conteúdo significativo no que diz respeito às propostas e garantias e direitos para a infância e adolescência. Embora não fale de Educação Infantil, aponta o que é a educação de crianças e reforça o direito desse grupo populacional ao atendimento nessa etapa educacional e faz referências às instituições que podem oferecer esse tipo de atendimento.

Em meados dos anos 1990, em meio a outras definições mais específicas em relação à Educação Infantil e resultado de um longo processo de discussão, foi promulgada a Lei de Diretrizes e Bases n. 9.394/96. A partir dessa lei a Educação Infantil passa a fazer parte da educação básica, portanto, deixou de ser de responsabilidade dos serviços de assistência social e começou a integrar os sistemas da educação. A Educação Infantil, como explicita a LDB, tem como finalidade garantir o desenvolvimento integral da criança, em seus aspectos físico, psicológico, intelectual e social, por conseguinte, complementa a educação dada pela família.

As instituições que devem oferecer o atendimento na Educação Infantil são creches ou entidades equivalentes para crianças de zero a três anos e pré-escolas para crianças de quatro e cinco anos, embora coexistam diferentes formatos de instituições públicas e privadas. Essa organização fica claramente explicitada nas instituições públicas. A 
iniciativa privada, embasada no princípio da livre iniciativa, assume outros formatos para atender a mesma demanda, porém com nomenclaturas e estruturas diferenciadas.

Como se percebe a LDB ampliou o que já havia sido assegurado pela Constituição de 1988, pois especifica finalidades, define responsabilidades relativas ao financiamento e estabelece os destinatários da Educação Infantil. Além disso, indica critérios referentes à formação mínima para o exercício do seu magistério.

No atual Plano Nacional de Educação (PNE) 2014-2024 a principal proposição para a Educação Infantil está expressa na meta 1, que destaca a ampliação do acesso, por meio da universalização da pré-escola e da expansão do atendimento em creches para no mínimo 50\% das crianças de até três anos. Admitimos que a ampliação do acesso é condição indispensável para a conquista da qualidade na Educação Infantil e para a garantia do direito subjetivo à educação. No entanto, a meta quantitativa para a creche ficou aquém das indicações da Conae/2010, que visava à progressiva universalização do atendimento à demanda na faixa etária de 0 a 3 anos de idade, em período integral, a critério das famílias. Na visão de Barbosa et al (2014), o tratamento dado às crianças de 0 a 6 anos no referido PNE, assume uma concepção que cinde creches e pré-escolas. Referem-se à continuidade de um tratamento discriminatório para as creches, isto é, para essas instituições se mantêm as mesmas prerrogativas do plano anterior, com muitas dificuldades de concretização.

Reconhecemos a partir da legislação que a criança brasileira é reconhecida como cidadã, sujeito de direitos, porém, apenas a parcela mais abastada da população tem tido acesso pleno à Educação Infantil. Diante desse impasse, consideramos relevante saber o que pensam os pais sobre educação infantil.

$\mathrm{O}$ acesso desigual a essa etapa educacional pode ser percebido por meio de variados aspectos, como: movimento das famílias de diferentes classes sociais em busca de vagas para os filhos pequenos nas instituições escolares; denúncia da insuficiência de vagas, pelos meios de comunicação. Ressaltamos que oferta insuficiente de vagas na Educação Infantil, pela rede pública, tem obrigado pais e mães de crianças pequenas a fazer vigílias nas portas das instituições consideradas de melhor qualidade, por exemplo, aquelas em que a comunidade se submete a longas listas de espera. Também nesse contexto, no período eleitoral, muitos candidatos aos poderes executivo e legislativo municipais usam oferta e ampliação da Educação Infantil como uma plataforma política.

Em relação à Educação Infantil identificamos uma realidade marcada por contradições entre a garantia do direito e precariedade da oferta. Diante disso, considerando que os pais e mães têm obrigação de buscar alternativas para atendimento às crianças nessa idade, neste artigo procuramos identificar as representações sociais 
de Educação Infantil construídas por pais e mães de crianças, usuárias de instituições públicas e privadas, que atendem crianças na faixa de zero a cinco anos, examinando o campo comum das representações sociais sobre Educação Infantil dessas famílias.

Entendemos que a apreensão das representações sociais de Educação Infantil, construídas por pais e mães de crianças usuárias de instituições públicas e privadas, poderá nos possibilitar uma melhor compreensão da dimensão simbólica do acesso e da prática desse direito, proclamado na sociedade desde o final dos anos 1980. Procuramos averiguar se, na visão desses pais e mães de crianças, a Educação Infantil contribui para o desenvolvimento da criança ou, apenas, é considerada como um espaço de cuidado e de segurança. Também, iremos identificar o papel atribuído ao professor que lida com essas crianças.

\section{REPRESENTAÇÕES SOCIAIS: A ABORDAGEM SOCIETAL}

Como referencial teórico metodológico, adotou-se a Teoria das Representações Sociais (TRS). A TRS valoriza o processo pelo qual os indivíduos, seres históricos e relacionados, atribuem sentido aos objetos. A necessidade do ser humano de se manter informado e de estar em sintonia com seu grupo faz com que acontecimentos, situações, objetos sejam explicados, levando assim à construção das representações sociais. Conforme Jodelet (2001), construímos representações porque temos necessidade de explicar o mundo que nos cerca. Procuramos nos ajustar e nos localizar física e intelectualmente, para resolver problemas decorrentes do contexto em que vivemos. Não somos isolados no vazio social e, portanto, necessitamos compartilhar o mundo com os outros e neles nos apoiar.

Este artigo, que toma como o objeto a Educação Infantil para pais e mães de crianças pequenas, adota a perspectiva societal das representações sociais, conforme W. Doise (2002).

A abordagem societal procura articular o individual ao coletivo, buscar a articulação de explicações de ordem individual com explicações de ordem societal, e evidenciar que os processos e mecanismos, usados pelos indivíduos em sociedade, são orientados por dinâmicas sociais (interacionais, posicionais ou de valores e de crenças gerais).

Doise e seus colaboradores, a respeito da influência de Piaget e Vygotsky, desenvolveram métodos experimentais com o objetivo de mostrar que o desenvolvimento cognitivo de certas operações resulta de interações sociais. Utilizando método experimental, evidenciam que há uma apropriação individual dos instrumentos cogni- 
tivos socialmente construídos e que as crianças se saem melhor em tarefas cognitivas quando as realizam em situações grupais ou com a ajuda de um adulto (DOISE, 2002).

O mesmo autor reconhece a TRS, de Moscovici, como um quadro mais estimulante para construir uma psicologia societal, portanto, articula o estudo dos sistemas cognitivos individuais aos estudos dos sistemas relacionais e societais. Dessa maneira, Doise (2002, p. 30) define "[...] as representações sociais como princípios organizadores das relações simbólicas entre indivíduos e grupos, que influenciam as tomadas de posição, ligados às inserções sociais específicas que interferem nas relações sociais."

As representações sociais, de acordo com a perspectiva do autor, podem ser tomadas como formas de compreensão e explicação da realidade, orientadas pelos grupos e pelas relações sociais de pertencimentos dos sujeitos. Uma representação social traz, em si, a marcação social do sujeito.

A abordagem societal sugere que os objetos de representação sejam estudados a partir de quatro níveis de análise: o primeiro diz respeito aos processos intraindividuais, que têm como base o modo como os indivíduos organizam suas experiências com o meio ambiente. O segundo centra-se nos processos interindividuais e situacionais, buscando nos sistemas de interação os princípios explicativos típicos das dinâmicas sociais. O terceiro refere-se aos processos intergrupais, considera as diferentes posições que os indivíduos ocupam nas relações sociais e analisa como essas posições modulam os processos do primeiro e do segundo níveis. O quarto, o societal, enfoca os sistemas de crenças, representações, avaliações e normas sociais, portanto, adota como pressuposto que as produções culturais e ideológicas, características de uma sociedade ou de certos grupos, dão significação aos comportamentos dos indivíduos, que criam as diferenciações sociais a partir de princípios gerais. A proposta de análise das RS a partir desses quatro níveis pauta-se na noção de RS como princípios geradores de tomadas de posição, ligados às inserções sociais específicas, que organizam os processos simbólicos que interferem nas relações sociais.

A articulação dos quatro diferentes níveis de análise (individual, interpessoal, grupal e societal) foi particularmente investigada por Doise e colaboradores, nos anos 1970, nos estudos das relações intergrupais. Para Doise (2002), a construção das representações depende das relações entre os grupos, à medida que serve para justificar o modo de encadeamento das relações, mantendo, ao mesmo tempo, a especificidade e identidade de cada grupo. No âmbito desses estudos sobre as relações intergrupais, o autor oferece uma relevante contribuição para a compreensão do funcionamento das identidades coletivas e individuais no processo de categorização social. 
O estudo das representações sociais, proposto pelo autor, coerente com esses pressupostos, orienta-se a partir de uma abordagem tridimensional, dividida em três fases, que correspondem a três hipóteses específicas: a primeira corresponde à identificação de um campo simbólico comum, ou seja, elementos compartilhados das representações entre os diferentes membros de uma população, acerca de um dado objeto social, aquilo que é consensual nessas representações. A segunda fase procura apreender os princípios geradores das diferenças individuais, a natureza das diferenças, das heterogeneidades nas tomadas de posições em relação a determinado objeto. Isto significa que, nessa segunda fase, é preciso identificar os princípios organizadores das variações individuais. A terceira fase busca identificar as ancoragens. Conforme o autor, as ancoragens estão baseadas nos jogos hierárquicos de valores, nas percepções oriundas das relações que os indivíduos estabelecem com os grupos e categorias, nas experiências sociais partilhadas com os outros em virtude de sua pertença e posição social. A busca da identificação das ancoragens dá ênfase à ancoragem das diferenças individuais.

O quadro teórico organizado por Doise (2002) remete a três hipóteses. A primeira é que os diferentes membros de uma população estudada partilham, efetivamente, de crenças comuns, concernentes a uma dada relação social. As representações sociais se constroem nas relações de comunicação, que supõem referentes ou pontos de referência comuns aos indivíduos e/ou grupos implicados nessas trocas simbólicas. A segunda hipótese refere-se à natureza das tomadas de posições individuais em relação a um campo de RS. Cabe à TRS explicar como e porque os indivíduos se diferenciam entre si nas relações que mantêm com essas representações. Portanto, as variações existentes nas tomadas de posição individuais são organizadas de uma maneira sistemática. A terceira hipótese considera que a ancoragem exerce influências nas tomadas de posição, que ocorrem em outras realidades simbólicas coletivas. Portanto, procura explicar hierarquias de valores, percepções construídas pelos indivíduos nas relações entre grupos, categorias e experiências sociais que são partilhadas.

Doise (2002) focaliza as representações sociais entre grupos e avalia esses processos, nos múltiplos contextos das relações grupais. Em consonância com o que explicitamos a respeito da abordagem tridimensional, Almeida (2009) afirma que a abordagem societal de Doise pressupõe a adoção de diversos fatores: estudo de indicadores que organizam o campo representacional; análise dos posicionamentos individuais nesse campo; e ancoragem dos posicionamentos nas dinâmicas societais. A abordagem possibilita análises mais elucidativas das diferenciações, que possam existir nas representações dos sujeitos vinculados a diferentes grupos. A variação na tomada de posição 
dos indivíduos, em relação à construção das $\mathrm{RS}$, é fruto de uma série de fatores, que são mobilizados a partir das suas pertenças dentro do contexto social.

Diante do exposto, podemos afirmar que a abordagem societal de Doise (2002) propicia os fundamentos metodológicos necessários para se capturar as representações sociais de Educação Infantil de grupos variados, compostos por pais e mães de crianças pequenas, que são oriundos de classes sociais heterogêneas: camadas populares, classes média e média alta. Focalizamos neste artigo a primeira dimensão do modelo de Doise, ou seja, o fenômeno foi investigado a fim de mostrar os elementos compartilhados da representação social de Educação Infantil de pais e mães de crianças vinculadas a instituições públicas e privadas que oferecem essa etapa da educação básica.

\section{PERCURSO METODOLÓGICO}

Para capturarmos o campo comum, ou consensual das representações sociais, utilizamos um questionário organizado em escalas do tipo Likert, com sentenças ou itens concernentes à Educação Infantil. De acordo com Gunther (2003), esse tipo de escala é usada com frequência no campo das Ciências Sociais, especialmente em pesquisas de levantamento de atitudes e opiniões entre grupos. Em geral, as escalas contêm quatro ou cinco alternativas, porém, o pesquisador pode fazer alterações e usar uma escala com dois, três, ou até nove itens, conforme seus objetivos. Na elaboração da escala analisada neste artigo, consideramos o que circula no senso comum sobre Educação Infantil e, também, sua natureza pedagógica e formativa. Construímos o referido instrumento enfocando as funções assumidas pela Educação Infantil, ao longo de sua história em nosso país.

A escala continha 20 itens relacionados a essas funções, que permitiram aos participantes apresentarem seus posicionamentos referentes aos aspectos e elementos, que são fundamentais, ou não, no atendimento educacional à criança pequena. Constitui um exemplo de item o seguinte: "ler e contar histórias para as crianças" é uma tarefa muito importante, mais ou menos importante ou pouco importante na Educação Infantil". Frente a cada item o participante se posicionava para a pesquisadora ou assinalava a coluna 5 quando concordava plenamente; coluna 3 quando concordava parcialmente e 1 se não concordava com o item proposto. Lembramos que com os sujeitos com menor nível de instrução a aplicação foi feita da seguinte forma: os itens contidos na escala eram lidos pela pesquisadora, que mediante resposta do participante, assinalava sua resposta no protocolo. 
Com base na sequência de itens comuns e não comuns, buscou-se identificar o que há de mais partilhado ou consensual nas representações sociais de Educação Infantil do grupo pesquisado.

O grupo participante foi constituído por 108 (cento e oito) sujeitos. Adotamos como critério de escolha, ser pai ou mãe de crianças efetivamente matriculadas em instituições de Educação Infantil, públicas e privadas da cidade do Recife-PE.

Para a análise do material coletado com escalas consideramos as frequências das escolhas por item (concordo, concordo parcialmente e não concordo). As respostas dos participantes que estavam mais concentradas no item um constituíram o grupo cujas representações sociais estão mais distantes da concepção de Educação Infantil e suas finalidades, no contexto atual. Tais respostas estão vinculadas a uma abordagem mais assistencial do educar crianças pequenas. As respostas concentradas na opção 3 foram indicativas de uma ambivalência em relação ao que seja Educação Infantil e um maior número de respostas no item 5 sugeriu uma representação de Educação Infantil compatível com o discurso pedagógico recente sobre seu caráter pedagógico, legislação e literatura atual.

\subsection{O GRUPO DE PAIS E MÃES: CARACTERÍSTICAS E PERTENÇAS}

Os 108 participantes estavam assim distribuídos: 57 tinham filhos matriculados em instituições públicas e 51 em instituições privadas de Educação Infantil. Houve maior participação de mães, (90) e menor de pais (18). No que concerne à faixa etária, o grupo pesquisado concentrou-se na faixa entre 23 e 29 anos de idade.

Quanto ao nível de instrução dos participantes com filhos em instituições públicas, 19 pais completaram o ensino médio; seis participantes concluíram o ensino fundamental; 10 deles não completaram o ensino médio; 19 não completaram o ensino fundamental e três não informaram.

Todos os participantes com filhos em instituições privadas declararam nível de instrução médio ou superior; sendo que mais da metade dos participantes (37) têm nível superior, dentre os quais 7 têm formação em nível de pós-graduação e 6 têm formação em nível médio e um deles não respondeu a esta pergunta.

Os dados sobre renda são diferenciados entre os dois grupos. A maior parte dos pais e mães (37) cujos filhos estão em instituições públicas apresentam renda entre um e dois salários mínimos; 13 informaram possuir renda de um a cinco salários 
mínimos, cinco deles possuem renda inferior a um salário mínimo e três não deram essa informação.

Do grupo de participantes com filhos em instituições privadas, 22 pais apresentam renda superior a cinco salários mínimos; 12 declararam renda acima de dez salários; 11 deles têm renda até cinco salários e três tinham rendas que ultrapassam dez salários mínimos. Três deles não informaram sobre os rendimentos.

\subsection{PAIS E MÃES DE INSTITUIÇÕES PÚBLICAS E PRIVADAS: O CONSENSUAL NAS REPRESENTAÇÕES SOCIAIS DE EDUCAÇÃO INFANTIL}

Definimos como consensual aqueles itens da escala que apresentaram $80 \%$ ou mais de indicações dos participantes de ambos os grupos. Desse modo, conforme ilustramos, na Tabela 1, o compartilhamento ocorreu em relação aos itens de números $6,8,10,11,16$ e 20 .

Tabela 1 - Itens compartilhados por mais de $80 \%$ do grupo pesquisado

Famílias de insti- Famílias de insti-

Item tuições privadas tuições públicas

\begin{tabular}{lllll}
\hline 6. A brincadeira deve ser incentivada nas instituições de & 47 & 86,2 & 50 & 87,7
\end{tabular}

Educação Infantil

8. Brinquedos diversos (jogos, blocos, bonecas) devem fazer parte do material didático das instituições.

$47 \quad 86,7 \quad 51 \quad 89,4$

10. Livros diversos de literatura infantil devem fazer parte do material da sala de Educação Infantil

$49 \quad 96,0 \quad 55 \quad 96,4$

11. A professora ler e contar histórias para as crianças deve ser algo comum na Educação Infantil.

$50 \quad 98,0 \quad 54 \quad 94,7$

16. As atividades, como pintura, rodas de história, cantigas, ateliês ou oficinas de desenho e música devem $\begin{array}{lllll}50 & 98,0 & 54 & 94,7\end{array}$ fazer parte da Educação Infantil

17. Deve ser considerada a formação/preparo para o exercício da função de professor(a) de Educação Infantil $48 \quad 94,1 \quad 51 \quad 89,7$ 20. A interação dos profissionais (professores, auxiliares, coordenadores) com as famílias é importante para o bom funcionamento da rotina escolar.

$49 \quad 96,0 \quad 54 \quad 94,7$

Fonte: os autores.

Nos itens de números 10, 11 e 16 detectamos um percentual expressivo de concordância entre os membros dos dois grupos pesquisados. Os pais e mães desta- 
caram as seguintes atividades: leitura, pintura, roda de história e música na Educação Infantil. Ressaltaram, também, as estratégias didáticas e pedagógicas, adequadas ao trabalho com as crianças nessa fase. Depreendemos que esse consenso decorre das implicações coletivas dos sujeitos (pais e mães) com o objeto (Educação Infantil). O compartilhamento desse conjunto de itens envolve e/ou resulta da comunicação e decisões que levam esses indivíduos e seus respectivos grupos na direção do que lhes convém, em consonância com suas normas e atitudes, referentes ao que convencionaram ser a função da Educação Infantil. Dessa forma, inferimos que o consenso relativo a esses itens está vinculado à realidade vivenciada nas instituições, ou seja, aos momentos lá vividos. Desse movimento interativo nas instituições, ressaltamos os seguintes elementos: reuniões de pais, momentos de discussão e apresentação da proposta de trabalho das instituições, conversas com outros pais e mães, diálogos com professores, acompanhamento de atividades realizadas na instituição ou em casa, observação da rotina, experiência cotidiana do ir deixar e buscar os filhos, enfim, das práticas vivenciadas por cada grupo.

Depreende-se, também, que o consenso está associado à configuração e exigências da sociedade, na qual a infância tem sido reconhecida e destacada pelos estudos sobre a criança e suas especificidades e, também, pelas leis que regem sua educação. No Brasil, conforme já citado neste trabalho, destacamos a LDB n. 9394/96, e o ECA, entre outras que proclamam o direito de cidadania à criança. Essa legislação, suas prerrogativas e implicações têm sido difundidas pelas mídias (jornais, televisão e rádio) e, também, pelo trabalho de entidades da sociedade civil, por exemplo, o conselho tutelar tem sido um divulgador dos direitos das crianças, especialmente, entre os grupos das camadas populares. Em paralelo, nas interações sociais e nas conversas dos grupos, esse assunto é, também, muito discutido. Podemos dizer que há uma pressão social em torno das famílias que, de certa forma, justifica o uso vocabulário corrente impregnado da importância da Educação Infantil como espaço de desenvolvimento da criança na atualidade. Identificamos, assim, a força dos mecanismos de difusão, propagação e propaganda que são veiculados pelos meios de comunicação para a construção das representações sociais dos dois grupos (MOSCOVICI, 2012).

Para o grupo de pais e mães de maior poder aquisitivo e com filhos matriculados nas instituições particulares a variável "nível de instrução" precisa ser destacada na construção de suas representações sociais da Educação Infantil. A maioria desses pais e mães possui formação superior e um capital econômico que sugerem melhores condições de acesso a uma malha de conhecimentos sobre o preconizado pelos documentos legais e outras leituras sobre o tema. Assim, o acesso à informação escrita e 
midiática, as comunicações diversas e mais sistemáticas sobre o objeto são absorvidas de modo diferenciado por esses sujeitos.

A valorização de Educação Infantil vem se concretizando, com "base" em duas representações distintas. De acordo com a primeira, durante a Educação Infantil a criança desenvolve-se pela convivência com outras crianças. A segunda pressupõe que a Educação Infantil oferece proteção e segurança às crianças, cujas mães precisam trabalhar. Em tais circunstâncias surgem pressões governamentais e, também, do mercado de trabalho. A esse respeito, Moscovici (2012) enfatiza que a convergência em relação a pontos particulares não decorre somente de afinidade da situação objetiva em torno desse objeto, mas da troca de opiniões entre as diversas fontes de informação nos grupos.

O item n. 20 alcançou percentuais muito próximos, nos dois grupos, pois os pais e mães consideram que as relações e interações (entre família e instituição) favorecem o desenvolvimento das crianças na Educação Infantil. No decorrer da aplicação da escala, os participantes de ambos os grupos ressaltaram a necessidade de um bom relacionamento com a equipe educacional, considerado como um fator indispensável para manter colaboração entre instituição e família e garantir o desenvolvimento da criança.

Conforme Silva (2009), a interação entre pais, professores e crianças torna-se um elemento indispensável, que oferece a todos a oportunidade de revelar saberes, ideias e expectativas acerca de um atendimento de qualidade, na Educação Infantil. Para Oliveira (2010), a gestão da relação entre instituição educacional e família varia conforme as situações, os sistemas e as tradições. A representação feita do papel da instituição pela família dependerá das influências que os pais e mães têm nesses espaços. Mas as expectativas a respeito da educação dos filhos, representações sociais e experiências pessoais de escolarização derivam, em parte, da situação socioeconômica e cultural da família.

A legislação atual, notadamente, a LDB, regulamenta a ação da Educação Infantil, considerada como primeira etapa da educação básica e complementar à ação da família, propõe, também, a articulação entre famílias e instituição. A normatização (legislação e outros documentos, como os curriculares - Diretrizes Curriculares Nacionais para a Educação Infantil e Referencial Curricular Nacional para a Educação Infantil) sugere constante diálogo, escuta cotidiana dos grupos familiares, estabelecimento de trocas de saberes, experiências e reconhecimento dessas famílias como participantes ativas do processo educativo. Os ditames da legislação e orientações curriculares para a Educação Infantil estimulam as instituições públicas e privadas a um bom entrosamento com as famílias. O entrosamento entre essas duas instâncias é complexo e, sobretudo, 
não pode ser decretado por lei, mesmo amparado e justificado pela legislação vigente. A efetivação desse entrosamento exige a adoção de práticas que promovam o diálogo e incentivem a participação dos pais nas atividades educativas e, também, no processo de aprendizagem da criança. O reconhecimento, de modo consensual, do valor da interação família/instituição para o desenvolvimento de crianças pequenas sinaliza que o desejado entrosamento já vem acontecendo nas instituições educativas. De acordo com os pais e mães, a interação família/instituição é fator que interfere no funcionamento da rotina institucional e no desenvolvimento das crianças.

$\mathrm{O}$ atual contexto exige que a educação e o cuidado com a criança pequena sejam compartilhados entre famílias e instituições educativas. Tais instâncias são distintas, no entanto, assumem papéis relevantes e legítimos no processo coletivo de educação das crianças pequenas, com a finalidade de oferecer condições para seu pleno desenvolvimento. No grupo pesquisado, identificamos um consenso a esse respeito.

$\mathrm{O}$ item de n. 6 da escala, referente à brincadeira, obteve um elevado índice de concordância entre mães e pais dos dois grupos, conforme demonstram os seguintes percentuais: $87,7 \%$ dos pais vinculados às instituições públicas e $86,2 \%$ dos pais, cujos filhos frequentam instituições privadas, concordam que a brincadeira deve ser estimulada na Educação Infantil. Tal compartilhamento não ocorre por acaso, pois a literatura sobre Educação Infantil vem enfatizando, de maneira constante, a brincadeira como um elemento constituinte da educação de crianças. Por exemplo, Santos (2001) afirma que ao brincar a criança experimenta, cria, recria, organiza-se, regula-se e constrói normas para si e para o outro. Para a autora, “[...] o brincar é uma forma de linguagem que a criança usa para compreender e interagir consigo mesma, com o outro e com o mundo." (SANTOS, 2001, p. 104). Para ambos os grupos pesquisados, a brincadeira foi tratada como indissociável, natural ao processo de desenvolvimento e acatada como inerente ao mundo infantil. Sobre essa relação desenvolvimento e brincadeira, Paniagua e Palacios (2005) consideram infância e brincadeira como sinônimos. Segundo esses autores, à medida que crescemos, brincamos menos, portanto, na idade correspondente à Educação Infantil a brincadeira é uma maneira de vivenciar o mundo. Não se trata, apenas, de diversão, pois a brincadeira oferece à criança diversas oportunidades, como: descobrir o mundo à sua volta; consolidar aprendizagens da vida cotidiana; estabelecer relações com outras crianças; e fortalecer seu processo de desenvolvimento cognitivo e social. Nos momentos de ludicidade, meninos e meninas têm possibilidades de expressar pensamentos, revelar sentimentos e, também, liberar/ fortalecer energias físicas. 
O brincar caracteriza-se como uma ação livre, que introduz o sujeito no mundo simbólico, podendo ser, espontaneamente, iniciado e conduzido pela criança. Inúmeras expressões e experiências podem ser conduzidas por meio do brincar. Com tal perspectiva, é fundamental planejar práticas pedagógicas que permitam o reconhecimento da diversidade das crianças, dos seus tempos e de sua cultura. Na Educação Infantil, a brincadeira permite que as crianças compreendam as ações pedagógicas com mais facilidade e obtenham maiores êxitos. Portanto, é considerada como ferramenta, que facilita a aprendizagem e o desenvolvimento da criança (KISHIMOTO, 2010).

A ludicidade tem sido um tema tratado sob vários enfoques na Educação Infantil e sua propagação vem se fortalecendo junto às instituições educativas. Por conseguinte, entre as famílias é consenso considerar o brincar como uma atividade inerente à prática pedagógica com criança pequena. Reconhecemos, ainda, que tal compartilhamento entre os grupos pesquisados está subsidiado por posicionamentos de especialistas no assunto, que circulam no meio acadêmico. Esse tema chega aos professores e aos pais por meio de variadas fontes: processos de formação inicial e continuada de professores; as interações entre pares; as experiências divulgadas pelas mídias; exigências legais; e literatura sobre educação. Assim, as instituições vão incorporando às suas propostas e às suas práticas o valor da brincadeira nessa fase de vida de crianças pequenas.

No item n. 8 e, também, nos itens 10, 11 e 16, constatamos que os pais e mães compartilharam opiniões a respeito de atividades comuns na Educação Infantil e identificaram os materiais que são adequados ao desenvolvimento das atividades propostas para as crianças, nessa fase. Há outro fator que merece destaque: as listas imensas de material escolar, solicitadas aos pais, principalmente, pelas instituições privadas, informam e validam o material didático utilizado no trabalho com crianças, na Educação Infantil. De acordo com Kishimoto (1994, p. 17), por exemplo, “[...] o jogo educativo surge no século XVI como suporte da atividade educativa didática, visando à aquisição de conhecimentos e conquista um espaço definitivo na educação infantil." Sob essa perspectiva, afirmamos que os pais pesquisados incorporaram ao seu universo simbólico o valor de pedagógico do uso de jogos, blocos e brinquedos, em decorrência de dois fatores: a experiência de adquirir material escolar e o contato sistemático com a instituição educativa.

No item de n. 17, referente à formação do professor para atuar na Educação Infantil, como já indicado, os dois grupos entraram em consenso, pois $89,4 \%$ dos pais e mães de instituições públicas e $94,1 \%$ das instituições privadas concordaram com sua importância. Na análise de cada grupo, a formação específica do professor 
de Educação Infantil é vista como um requisito indispensável ao desenvolvimento do trabalho junto às crianças. A qualificação profissional possibilita que o professor ultrapasse suas subjetividades e, sobretudo, evita que seu trabalho seja pautado, apenas, na amorosidade. Por conseguinte, a qualificação docente transmite confiança e segurança aos pais.

Sobre o assunto, convém lembrar que a atual LDB, em seu artigo 62, estabelece a necessidade da formação superior para o professor que atuará na Educação Infantil. Recentemente, tal determinação foi reforçada pela Lei n. 12.796/2013. Segundo os dispositivos legais, a formação de docentes para atuar na educação básica deverá ser feita em nível superior, em curso de licenciatura, de graduação plena, em universidades e institutos superiores de educação. Como formação mínima para o exercício do magistério na Educação Infantil e nos cinco primeiros anos do ensino fundamental, é admitida, ainda, a formação docente em nível médio.

Podemos inferir que informações referentes ao conteúdo das leis foram incorporadas e povoam a representação social, de parte considerável, dos dois grupos de pais e mães de crianças ouvidos na investigação. Mesmo que os sujeitos pertençam a grupos sociais diferentes, eles recebem influências das mídias e estão submetidos a pressões da sociedade de comunicação. A exigência por escolarização tem sido cada vez maior, mesmo para o exercício de atividades mais simples As propagandas, especialmente, as televisivas, que têm amplo acesso junto à população, apresentam o ensino superior como caminho promissor para o melhor emprego e espaço no competitivo mercado. Tais propagandas midiáticas influenciam alguns pais e mães, que consideram Educação Infantil como uma promessa de sucesso na escolarização futura.

Depreendemos que a frequência das respostas ao questionário apresentou-se, de forma semelhante, nos dois grupos.

\section{CONSIDERAÇÕES FINAIS}

Identificamos entre pais e mães de crianças um conteúdo consensual de Educação Infantil centrado na valorização dos seguintes aspectos: brincadeira, utilização de material concreto e, também, leitura e contação de histórias pelas professoras. Em geral, as famílias compartilham da compreensão de que a Educação Infantil é a base da formação. Nos dois grupos de pais e mães, há um reconhecimento coletivo de que sua oferta ocorre em estabelecimentos oficiais e particulares; que as instituições devem trabalhar de maneira integrada e cooperativa com as famílias, com a finalidade de garantir o desenvolvimento das crianças. 
Reiteramos que o conteúdo desse consenso representacional é fruto de implicações e convergências situadas nas comunicações dos participantes, portanto, não pode ser considerado sem considerar os vínculos de pertença do sujeito aos grupos. Esse consenso resulta de afinidades em relação ao objeto e, principalmente, das trocas de opiniões entre pessoas, conhecimentos provenientes das mais diferentes fontes. Moscovici e Doise (1991, p. 5) afirmam que: “[...] somos forçados a concluir que, até certo ponto, a comunicação constrói consensos mediante artifícios de retórica que dão um peso excessivo aos argumentos de alguns grupos e enviesam as escolhas."

Insistimos, portanto, no papel e nas influências da comunicação para as dinâmicas, ações e condutas dos grupos pesquisados. O compartilhamento de representações dos grupos no que se refere à Educação Infantil está vinculado às normas, condutas, valores e crenças que permeiam as comunicações. Segundo Doise e Moscovici (1991), o consenso faz parte de um processo comunicacional complexo, que leva o sujeito a fazer escolhas, assumir posições, comportar-se frente a determinadas questões que são postas mediante acordos sociais aceitos, tacitamente, pelos grupos.

Nota explicativa

${ }^{1}$ A Lei n. 11.274 de 20 de fevereiro de 2006 alterou a redação dos artigos 29, 30, 32 e 87 da Lei n. 9.394/96. Dispõe sobre a duração do ensino fundamental de 9 (nove) e redução da Educação Infantil de 0 a 6 para de 0 a 5 anos.

\section{REFERÊNCIAS}

ALMEIDA, A. M., Abordagem Societal das Representações Sociais. Sociedade e Estado, Brasília, DF, 2009.

BARBOSA, I. G.; et al. Revista Retratos da Escola, Brasília, DF, v. 8, n. 15, p. 505-518, jul./dez. 2014. Disponível em: <http//www.esforce.org.br $>$. Acesso em: 23 maio 2015.

BRASIL. Constituição da República Federativa do Brasil. Brasília, DF: Senado, 1988.

BRASIL. Diretrizes Curriculares Nacionais para a Educação Infantil. Brasília, DF: CNE/CEB, 1999.

BRASIL. Estatuto da Criança e do Adolescente. Lei Federal n. 8.069, de 13 de julho de 1990. 
BRASIL. Lei de Diretrizes e Bases da Educação Nacional n. 9.394, de 20 de dezembro de 1996. Dispõe sobre as Diretrizes e Bases da Educação Nacional. Brasília-DF, 1996.

BRASIL. Lei n. 11.274, de 06 de fevereiro de 2006. Altera a redação dos arts. 29, 30, 32 e 87 da Lei no 9.394, de 20 de dezembro de 1996, que estabelece as diretrizes e bases da educação nacional, dispondo sobre a duração de 9 (nove) anos para o ensino fundamental, com matrícula obrigatória a partir dos 6 (seis) anos de idade. Diário Oficial da União, Brasília, DF, 07 fev. 2006. Disponível em: < http://www. planalto.gov.br/ccivil_03/_ato2004-2006/2006/lei/111274.htm>. Acesso em: 23 maio 2015.

BRASIL. Ministério da Educação e do Desporto. Referencial Curricular Nacional para a Educação Infantil. Brasília, DF: MEC, 1998.

CAMINO, L. et al. A Face Oculta do Racismo no Brasil: Uma Análise Psicossociológica. Psicologia Política, p. 13-36, 2000.

CORRÊA, B. C. Gestão democrática e participação familiar no âmbito da educação infantil. In: REUNIÃO ANUAL DA ANPED, 25., 2002, Caxambu, Anais eletrônicos... Caxambu-MG: ANPED, 2002. Disponível em: <http//www.anped.or.br>. Acesso em: 23 maio 2015.

DOISE, W. Da psicologia Social a Societal. Psicologia: Teoria e Pesquisa, v. 18, n. 1, p. 27-35, 2002.

GÜNTHER, H. Como Elaborar um Questionário. Brasília: UnB, Laboratório de Psicologia Ambiental, 2003. (Série: Planejamento de Pesquisa nas Ciências Sociais, n. 1).

JODELET, D. Representações sociais: um domínio em expansão. In: As Representações Sociais. Rio de Janeiro: Eduerj, 2001.

KISHIMOTO, T. M. O jogo e a educação infantil. Pioneira, São Paulo, 1994.

KISHIMOTO, T. M., A LDB e as instituições de educação infantil: Desafios e perspectivas. Educação, São Paulo, p. 7-14, 2010. Suplemento n. 4.

MOSCOVICI, S.; DOISE, W. Dissensões e consenso: uma teoria geral das decisões coletivas. Tradução Maria Fernanda Jesuíno. Lisboa: Livros Horizonte, 1991.

MOSCOVICI, S. A Psicanálise, sua imagem e seu público. Petrópolis: Vozes, 2012. 
MOSCOVICI, S. A Representação Social da Psicanálise. Tradução Álvaro Cabral. Rio de Janeiro: Zahar, 1978.

OLIVEIRA, Z. R. O currículo na Educação Infantil: o que propõem as novas Diretrizes Nacionais? Anais do Seminário Nacional: currículo em movimento perspectivas atuais, Belo Horizonte. 2010.

PANIAGUA, G.; PALACIOS, J. Educação Infantil: Resposta Educativa à diversidade. Artmed: Porto Alegre, 2005.

SANTOS, V. L. B. Promovendo o desenvolvimento do faz de conta na educação infantil. In: CRAIDY, C. M.; KAERCHER, G. (Org.). Educação infantil: pra que te quero? Porto Alegre: Artmed, 2001.

SILVA, Ana Paula Soares. Apresentação da série Educação de crianças em creches. In: Educação de crianças creches. Salto para o futuro/ TV Escola. Brasília, DF: SEED / MEC, 2009.

Recebido em 29 de outubro de 2015

Aceito em 08 de fevereiro de 2016

Endereço para correspondência: Avenida Professor Moraes Rego, 1235, Cidade Universitária, 50670-901, Recife, Pernambuco, Brasil; laeda01@gmail.com; luzdois@ yahoo.com.br 